\title{
P18 peptide, a functional fragment of pigment epithelial-derived factor, inhibits angiogenesis in hepatocellular carcinoma via modulating VEGF/VEGFR2 signalling pathway
}

\author{
XIN WANG, PENG XIU, FUHAI WANG, JINGTAO ZHONG, HONGLONG WEI, \\ ZONGZHEN XU, FENG LIU and JIE LI \\ Department of General Surgery, Qianfoshan Hospital Affiliated to Shandong University, Jinan, Shandong 250014, P.R. China
}

Received December 29, 2016; Accepted May 30, 2017

DOI: $10.3892 /$ or.2017.5719

\begin{abstract}
The P18 peptide is a functional fragment of pigment epithelial-derived factor (PEDF), which is an endogenic angiogenesis inhibitor. This study sought to determine the anti-angiogenic bioactivity of the $\mathrm{P} 18$ peptide in hepatocellular carcinoma (HCC) and to elucidate the underlying mechanism. Xenograft tumour growth assays demonstrated the P18 peptide suppressed angiogenesis of HCC in vivo. Wound healing, Transwell and Matrigel-culture assays indicated that the $\mathrm{P} 18$ peptide inhibited the cell migration and tube formation of endothelial cells (ECs) in vitro. Cell viability and apoptosis assessed by Cell Counting Kit-8 (CCK-8) and flow cytometry assays suggested that the P18 peptide inhibited angiogenesis by inducing apoptosis of ECs. Angiogenesis- and signal transduction-associated molecules analysed by western blot demonstrated that the P18 peptide targets vascular endothelial cell growth factor receptor 2 (VEGFR2) on ECs. In conclusion, by inhibiting the phosphorylation of VEGFR2, the P18 peptide modulates signalling transduction between VEGF/VEGFR2 and suppresses activation of the PI3K/Akt cascades, leading to an increase in mitochondrial-mediated apoptosis and anti-angiogenic activity. This bioactivity of the P18 peptide may represent a novel therapeutic strategy for the treatment of HCC.
\end{abstract}

\section{Introduction}

Angiogenesis refers to the formation of new blood vessels from existing capillaries or via intravenous development. The complete process of angiogenesis involves a variety of cells and molecules that play roles in vascular basement

Correspondence to: Professor Jie Li, Department of General Surgery, Qianfoshan Hospital Affiliated to Shandong University, 16766 Jingshi Road, Jinan, Shandong 250014, P.R. China

E-mail: lijieqfs@126.com

Key words: angiogenesis, P18 peptide, VEGF, VEGFR2, apoptosis, hepatocellular carcinoma membrane degradation as well as in the subsequent vascular endothelial cell activation, proliferation, migration and reconstruction (1). In the process of tumour development, angiogenesis is a necessary prerequisite and is regulated by a balance between pro-angiogenic factors, such as vascular endothelial cell growth factor (VEGF), basic fibroblast growth factor (bFGF) and angiopoietin, and anti-angiogenic factors, such as tumstatin, endostatin and thrombospondin-1 (2-4). Hepatocellular carcinoma (HCC) is one of the most common types of carcinoma and is characterized by an enriched blood supply. The progression of angiogenesis is vital for tumour occurrence and development and is closely associated with HCC metastasis, invasion and resistance to therapy $(5,6)$. Thus, several anti-angiogenic drugs (such as sorafenib) have been recommended for clinical applications as treatment options for patients with advanced stage $\operatorname{HCC}(7,8)$.

Pigment epithelial-derived factor (PEDF) is a multifunctional glycoprotein that belongs to a family of non-inhibitory serpins. Among naturally occurring anti-angiogenic factors, PEDF is considered an effective angiogenesis inhibitor $(9,10)$. However, PEDF comprises multiple functional fragments that are responsible for several functions, such as inhibition of angiogenesis and promotion of survival and neuro-differentiation. Previous studies have demonstrated that the anti-angiogenic functional fragment of PEDF is located at the NH2-terminal surface epitope (the 34-mer amino acid residues 24-57, PEDF-34mer), while the prosurvival and neuro-differentiating functional fragments are located at the adjacent epitope (44-mer residues 58-101, PEDF 44-mer) (11-13). Studies have revealed that PEDF inhibits the development of several malignant tumours, such as lung carcinoma, osteosarcoma and pancreatic carcinoma (14-16). However, although the in vivo overexpression of full-length PEDF is beneficial for inhibiting tumour growth, its application in clinical treatments is limited due to its low stability and immune antigenicity. Therefore, short but stable peptides derived from PEDF that are as effective at inhibiting angiogenesis as the full-length PEDF fragments could have more practical value in clinical practice. The P18 peptide is an angioinhibitory epitope of PEDF 34-mer (18-mer residues 40-57) that has been proposed to be a bioactive antiangiogenic fragment. A previous study demonstrated that the 
P18 peptide exerted activity analogous to that of full-length PEDF in prostate and renal carcinoma (17). However, the effects of the P18 peptide on angiogenesis in HCC and its applicability in tumour therapy remain unclear.

VEGF is a potent pro-angiogenic cytokine that is also known to promote proliferation and survival of endothelial cells (ECs) as well as vascular permeability $(18,19)$. VEGF is expressed in vascularized tissues and is critical for normal and pathological angiogenesis. Substantial evidence has implicated VEGF in the induction of tumour proliferation, metastasis and angiogenesis $(3,20,21)$. VEGF165, the predominant isoform of VEGF in humans, signals through three receptors: fms-like tyrosine kinase (flt-1, also VEGFR1), KDR gene product (KDR, also VEGFR2) and the flt4 gene product (flt-4, also VEGFR3). Among these three receptors, VEGFR2 is a major receptor for VEGF-induced signalling in endothelial cells (3,22-24). Previous studies have detected VEGFR2 not only in vascular endothelial cells but also its overexpression in many types of malignant solid tumours (25). Upon binding with VEGF, VEGFR2 undergoes autophosphorylation and becomes activated. Phosphorylation of Tyr1175 allows binding with the p85 subunit of the PI-3 kinase (PI3K), which leads to activation of the PI3K/Akt signalling pathway (26). This VEGFR2 signalling is necessary for the execution of VEGFstimulated proliferation, chemotaxis and sprouting as well as for the survival of cultured endothelial cells in vitro and angiogenesis in vivo $(20,24)$.

Existing evidence has indicated that VEGFR2 is a target of PEDF $(9,27)$. However, whether the P18 peptide can block VEGF/VEGFR2 signal transduction and ultimately lead to the inhibition of angiogenesis in HCC remains unclear. Thus, we designed the present study to identify the mechanism by which the P18 peptide inhibits angiogenesis in HCC. We observed that the P18 peptide counteracted the bioactivity of VEGF and suppressed cell activity by reducing the secretion of cadherins (VE-cadherin and E-cadherin) and matrix metalloproteinases (matrix metalloproteinase-2, MMP-2 and MMP-9) in both human umbilical vein and microvascular endothelial cells (HUVECs) and HepG2 hepatoma cells in vitro, which resulted in the suppression of invasiveness and pro-angiogenesis of endothelial cells. Moreover, our xenograft tumour model also provided evidence that the P18 peptide downregulates the phosphorylation of VEGFR2 and inhibits angiogenesis of HCC in vivo. We demonstrated that the $\mathrm{P} 18$ peptide may act on ECs by modulating the VEGF/VEGFR2 signalling pathway and it induced PI3K/Akt cascades, which would lead to apoptosis of ECs and reduced neovascularization.

\section{Materials and methods}

Cell lines and culture. Human umbilical vein and microvascular endothelial cells (HUVECs) and human HCC cell line HepG2 cells were purchased from the Typical Culture Reserve Center of China (Shanghai, China) and cultured under $5 \% \mathrm{CO}_{2}$ in ECM-2 medium (ScienCell Research Laboratories, Carlsbad, CA, USA) supplemented with $5 \%$ foetal bovine serum (FBS, Gibco, Grand Island, NY, USA), 100 U/ml penicillin, $100 \mu \mathrm{g} / \mathrm{ml}$ streptomycin and $1 \%$ endothelial cell growth supplement (ECGS, ScienCell Research Laboratories). The human HCC cell line HepG2 was obtained from the
American Type Culture Collection (Rockville, MD, USA) and cultured in Dulbecco's modified Eagle's medium (DMEM, Hyclone, Thermo Fisher Scientific Inc., Logan, UT, USA) supplemented with $10 \%$ FBS (Gibco), $100 \mathrm{U} / \mathrm{ml}$ penicillin and $100 \mu \mathrm{g} / \mathrm{ml}$ streptomycin. A hypoxia incubator was used to simulate hypoxic conditions $\left(1 \% \mathrm{O}_{2}, 5 \% \mathrm{CO}_{2}\right.$ and $\left.94 \% \mathrm{~N}_{2}\right)$.

Antibodies and reagents. Antibodies against VEGFR2, phosphorylated (p)-VEGFR2 (Tyr1175), PI3K, p-PI3K p85 (Tyr458)/p55 (Tyr199), Akt, p-Akt (Ser473), Bax, Bcl-2, caspase-3, cleaved caspase-3, MMP-2, MMP-9 and CD31 were purchased from Cell Signalling Technology (Danvers, MA, USA). Antibodies against VEGF, VE-cadherin, E-cadherin, $\mathrm{Ki67}$, GAPDH and $\beta$-actin were purchased from Abcam (Cambridge, UK). Horseradish peroxidase (HRP)-conjugated goat anti-rabbit IgG and HRP-conjugated mouse IgG were purchased from Beyotime Institute of Biotechnology (Jiangsu, China). Recombinant P18 peptide ( $>95 \%$ purity) was purchased from GL Biochem Ltd. (Shanghai, China) and characterized by mass spectrometry. The peptides were acetylated at their $\mathrm{NH} 2$ termini and amidated at their $\mathrm{COOH}$ termini for stability. SU1498, a selective VEGFR2 inhibitor, was acquired from Abcam. Recombinant human VEGF (VEGF165) and recombinant human IGF-1 were obtained from PeproTech (Rocky Hill, NJ, USA). Matrigel was purchased from BD Biosciences (San Jose, CA, USA).

Cell viability assay. HUVECs $\left(5 \times 10^{3} /\right.$ well) or HepG2 cells $\left(5 \times 10^{3} /\right.$ well $)$ were seeded in three 96 -well plates. After cell attachment, the supernatants in the plates was replaced with ECM containing gradient concentrations of the P18 peptide $(10,20,40,80,160,320,640$ and $1280 \mathrm{nM})$. The plates were numbered as plate 1 , plate 2 and plate 3 and incubated at $37^{\circ} \mathrm{C}$ under $5 \% \mathrm{CO}_{2}$. Viable cells were quantified by Cell Counting Kit-8 (CCK-8, Dojindo Molecular Technologies, Kumamoto, Japan) assay at various time-points (plate 1:24 h, plate $24: 8 \mathrm{~h}$ and plate 3:72 h). The optical density (OD) at $450 \mathrm{~nm}$ was measured using a Spectra Max 190 (Molecular Devices, Sunnyvale, CA, USA).

Western blot analysis. The cells or frozen tumour samples were lysed in cold RIPA lysis buffer (Beyotime, Beijing, China) with $1 \mathrm{nM}$ phenylmethylsufonyl fluoride. A BCA Protein Assay kit (Beyotime) was used to measure the concentration of the protein samples. Total protein (20-25 $\mu \mathrm{g})$ was separated via SDS-PAGE gels and transferred to PVDF membranes (Millipore, Billerica, MA, USA). The membranes were blocked with $5 \%$ skimmed milk for $2 \mathrm{~h}$ at room temperature and then incubated with primary antibodies at $4^{\circ} \mathrm{C}$ overnight according to the manufacturer's instructions. The membranes were then incubated with HRP-conjugated antimouse or rabbit IgG secondary antibody (Beyotime) for $2 \mathrm{~h}$ at room temperature, followed by detection using enhanced chemiluminescence (ECL) immunoblotting detection reagents (Millipore). Protein band intensities were quantified via densitometric analysis using ImageJ software (National Institutes of Health, Bethesda, MD, USA).

Xenograft tumour growth assay. HepG2 cells $\left(5 \times 10^{6} / 0.1 \mathrm{ml}\right)$ in PBS were inoculated into the dorsal area near front leg 
A

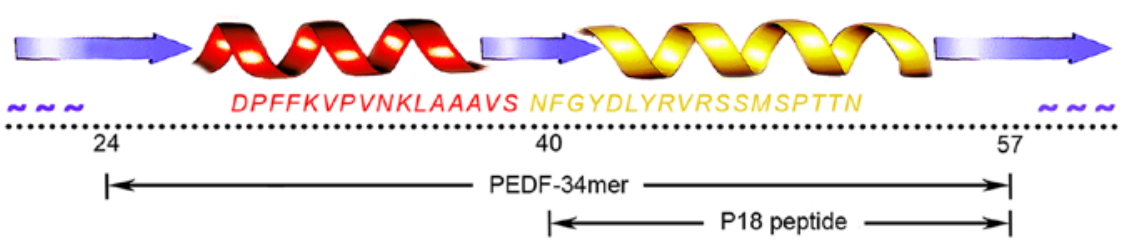

B

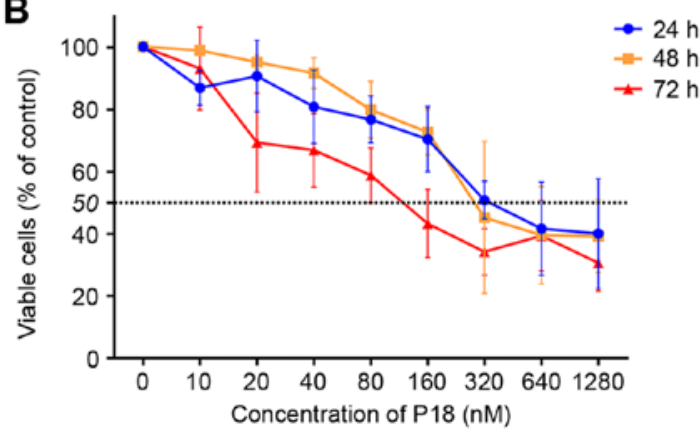

C

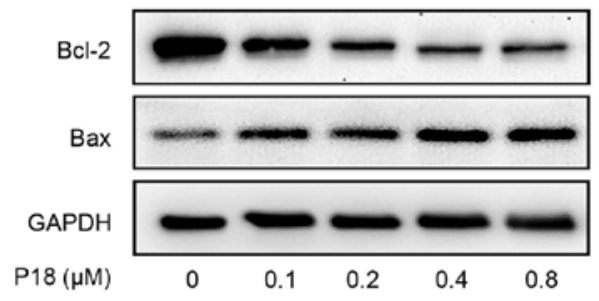

Figure 1. The P18 peptide inhibits EC proliferation in vitro. (A) The amino acid sequence of the P18 peptide. (B) Dose titration of HUVEC proliferation. Viable cells were quantified by CCK- 8 assays. The data represent the absorbance as a percentage of their respective controls and are expressed as the mean \pm SD. $(\mathrm{C})$ Expression levels of Bcl-2 and Bax in HUVECs treated with an ascending concentration gradient of the P18 peptide and analysed by western blotting.

of 4-week-old BALB/c nude mice (Shanghai Laboratory Animal Company, Shanghai, China). The mice were observed until tumours reached a volume of $100 \mathrm{~mm}^{3}$. Then, the mice were randomized into three groups ( 5 in each group) and marked. The two experimental groups were administered an intraperitoneal injection of $\mathrm{P} 18$ peptide (dissolved with $0.9 \%$ normal saline) at doses of $0.1 \mathrm{mg} / \mathrm{kg}$ (dose/mouse body weight) or $0.5 \mathrm{mg} / \mathrm{kg}$. The control group was treated with the same volume of $0.9 \%$ normal saline $(0.9 \% \mathrm{NS})$. Tumour growth was monitored by the length and width of the tumour acquired from external measurements every 2 days. Tumour volume was determined according to the following equation: volume $\left(\mathrm{mm}^{3}\right)=\left(\right.$ length $\mathrm{x}$ width $\left.{ }^{2}\right) / 2$. Fourteen days after the first injection, the mice were sacrificed, and the tumours were excised and weighed. All experiments were performed following approval by the ethics committee of Qianfoshan Hospital.

Immunofluorescence (IF) assay. The xenogeneic tumours were frozen in liquid nitrogen immediately after the mice were sacrificed and then frozen in $5-\mu \mathrm{m}$ sections. The sections were fixed in $4 \%$ paraformaldehyde for $20 \mathrm{~min}$. After blocking in 5\% BSA for $1 \mathrm{~h}$, the sections were incubated at $4{ }^{\circ} \mathrm{C}$ overnight with goat polyclonal anti-VEGF (Novus, San Diego, USA) and rabbit monoclonal anti-phosphorylated VEGFR2. Cells or mouse sections were then incubated with donkey anti-goat FITC-labelled (Abcam) and donkey antirabbit TRITC-labelled (Abcam) secondary antibodies for $2 \mathrm{~h}$ and were stained with DAPI (Abcam). Fluorescent images from tissues were photographed using a light microscope, and double immunofluorescent staining were merged using Image-Pro Plus software.

Immunohistochemistry (IHC) assay. Tumour simples were fixed in $10 \%$ formalin, embedded in paraffin and then processed for immunohistochemistry. The sections were deparaffinized in graded xylene and rehydrated in graded ethanol, and then washed with PBS 3 times. After heat-induced antigen retrieval in citrate buffer, endogenous peroxidase was inhibited by treatment with $3 \%$ hydrogen peroxide at room temperature for $10 \mathrm{~min}$, followed by washing 3 times with PBS. The sections were then incubated with primary anti-VE cadherin, anti-CD31 and anti-Ki67 antibodies overnight. After washing with PBS, the sections were treated with horseradish peroxidase (HRP)-conjugated goat anti-rabbit $\operatorname{IgG}$ for $1 \mathrm{~h}$ at $37^{\circ} \mathrm{C}$. Negative control sections were incubated with PBS instead of the primary antibody.

Wound-healing assay. HUVECs were seeded in 6-well plates. When the cells were $90 \%$ confluent, a wound line was made using a $10-\mu 1$ plastic pipette tip. The cells were then incubated in serum-free ECM-2 medium with VEGF $(8 \mathrm{ng} / \mathrm{ml})$ with or without P18 peptide $(0.2 \mu \mathrm{M})$. The wound-healing processes were photographed at time points 0,12 and $24 \mathrm{~h}$, and the cell migration distance was quantified by analysing the images.

Migration and invasion assay. A Transwell cell migration system (8- $\mu \mathrm{m}$, Corning Inc., Corning, MA, USA) coated with Matrigel was used to perform the cell migration and invasion assays. HUVECs $\left(1 \times 10^{5} /\right.$ well) or HepG 2 cells $\left(5 \times 10^{4} /\right.$ well $)$ were added to the upper chamber of a Transwell plate, and $500 \mu 1$ of serum-free medium with or without VEGF $(8 \mathrm{ng} / \mathrm{ml})$ and the P18 peptide $(0.2 \mu \mathrm{M})$ was added to the lower chamber. After $48 \mathrm{~h}$ of incubation, the migrated cells were fixed with $95 \%$ methanol and stained with $0.1 \%$ crystal violet for $30 \mathrm{~min}$ followed by washing 5 times with PBS.

Tube formation assay. Each well of 96-well plates was coated

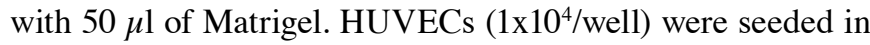
the wells following solidification of the Matrigel. The cells in the experimental groups were treated with P18 peptide $(0.2 \mu \mathrm{M})$, and the control groups were treated with an equal volume of PBS. The cells were incubated at $37^{\circ} \mathrm{C}$ with $5 \%$ $\mathrm{CO}_{2}$ for $6 \mathrm{~h}$ and then photographed using a light microscope (Olympus, Tokyo, Japan). 
A
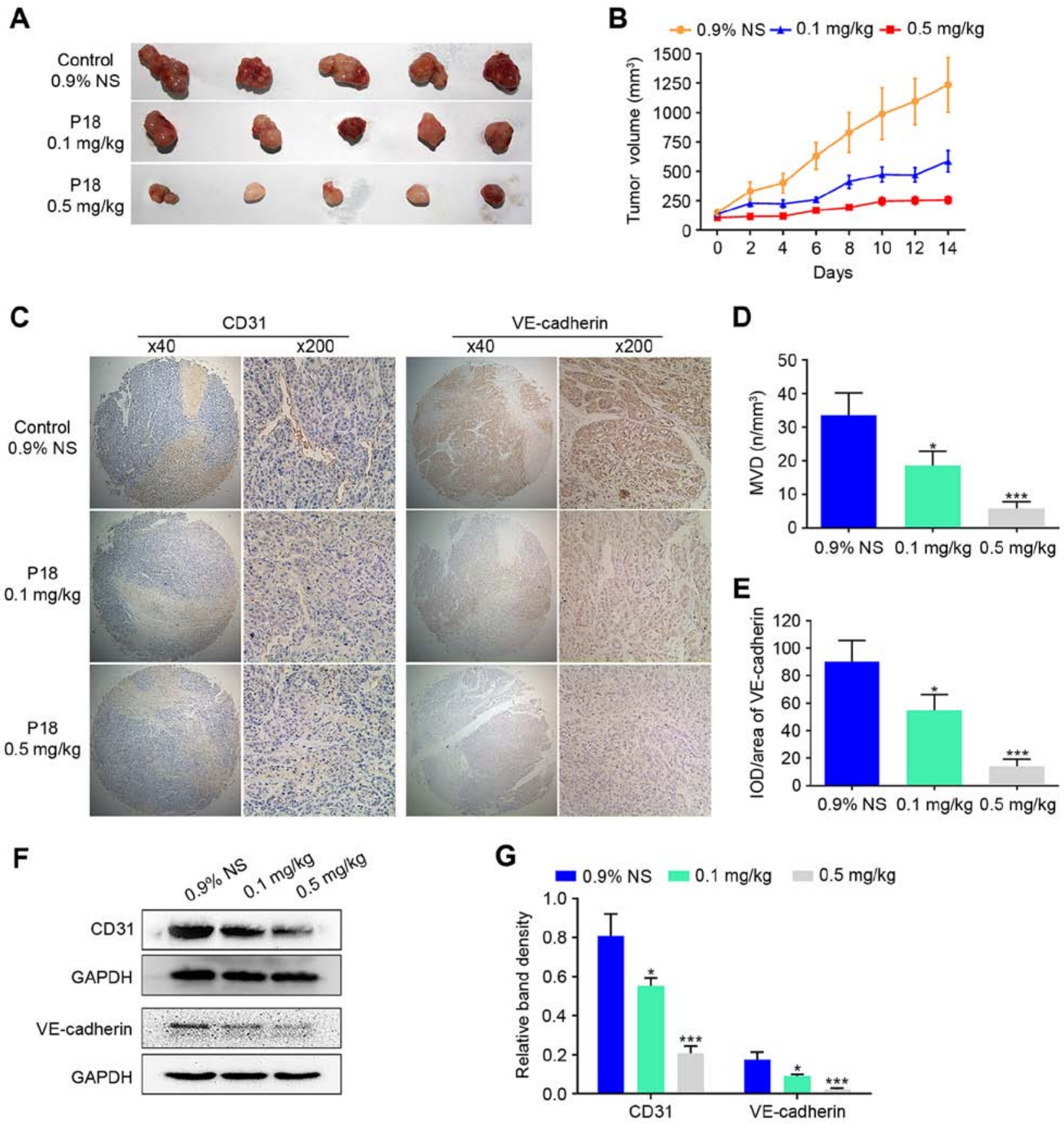

Figure 2. The P18 peptide suppresses tumour growth and angiogenesis of HCC in vivo. (A) Tumour tissue on day 14 after injection with $0.9 \%$ NS or different doses of P18. (B) Curve of tumour growth suppression is shown as tumour volume after treatment with $0.9 \%$ NS or different doses of P18 (mean \pm SD). (C) Results of IHC staining for CD31 and VE-cadherin in tumour tissues (magnification, $\mathrm{x} 200$ ). (D) Data represent MVD in tumour tissues (mean \pm SD, ${ }^{*} \mathrm{P}<0.05$, ${ }^{* * * *} \mathrm{P}<0.01$ ). MVD was determined via IHC staining with an endothelial-specific antibody against CD31 (magnification, $\mathrm{x} 200$ ). (E) The P18 peptide inhibited expression of VE-cadherin, a molecular marker of angiogenesis, in HCC tumour tissue (magnification, $\mathrm{x} 200$ ). The data represent IOD/Area (mean $\pm \mathrm{SD}$, $\left.{ }^{*} \mathrm{P}<0.05,{ }^{* * * *} \mathrm{P}<0.01\right)$. (F) Expression of CD31 and VE-cadherin were detected by western blot assays. (G) The density of each band in western blot assay was quantified and normalized to that of GAPDH (mean $\left.\pm \mathrm{SD},{ }^{*} \mathrm{P}<0.05,{ }^{* * * *} \mathrm{P}<0.01\right)$.

Cell apoptosis assay. HUVECs (4x105/well) or HepG2 cells $\left(4 \times 10^{5} /\right.$ well) were treated with or without the P18 peptide and incubated for $24 \mathrm{~h}$. Then, the cultured cells were suspended in PBS, counted and resuspended with binding buffer. Annexin V-FITC and propidium iodide (PI; NeoBioscience Ltd., Shenzhen, China) were used to detect the apoptosis rate of the cells via a flow cytometry assay.

Statistical analysis. The data were analysed with SPSS software (version 17.0, SPSS China, Shanghai, China) and expressed as the mean \pm standard deviation (SD). Student's t-tests were used for comparisons between 2 groups, and one-way analysis of variance was used for comparisons between multiple groups. P-values $<0.05$ were considered to indicate statistically significant results.

\section{Results}

P18 peptide inhibits ECs proliferation in vitro. The $\mathrm{P} 18$ peptide was synthesized according to the amino acid sequence shown 
A

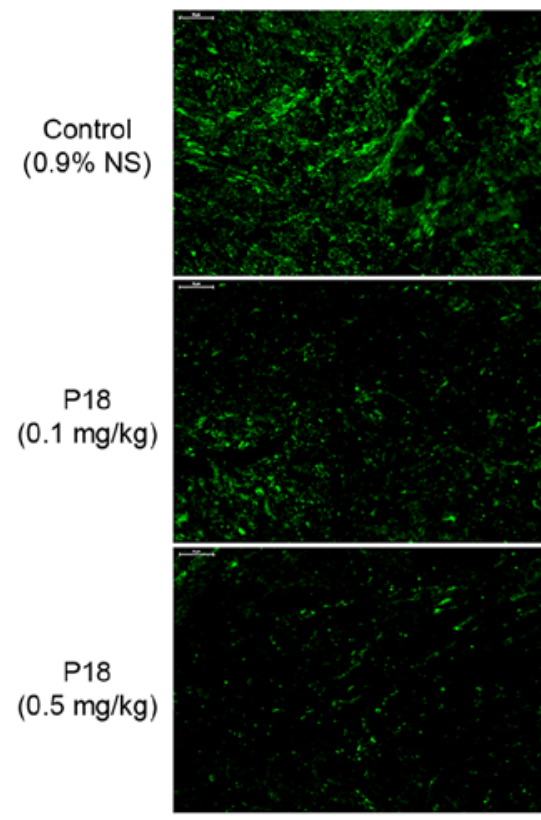

B

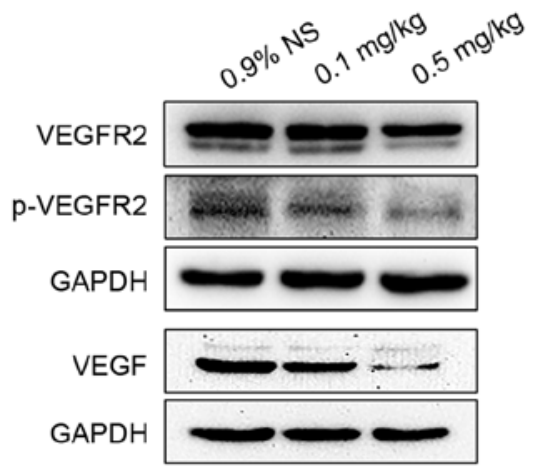

p-VEGFR2

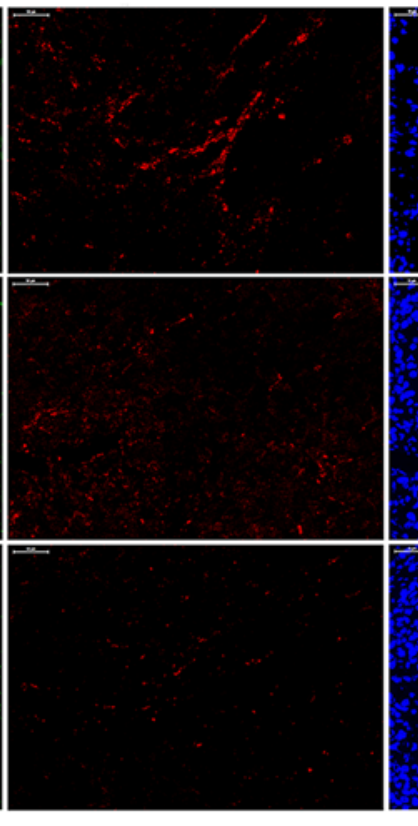

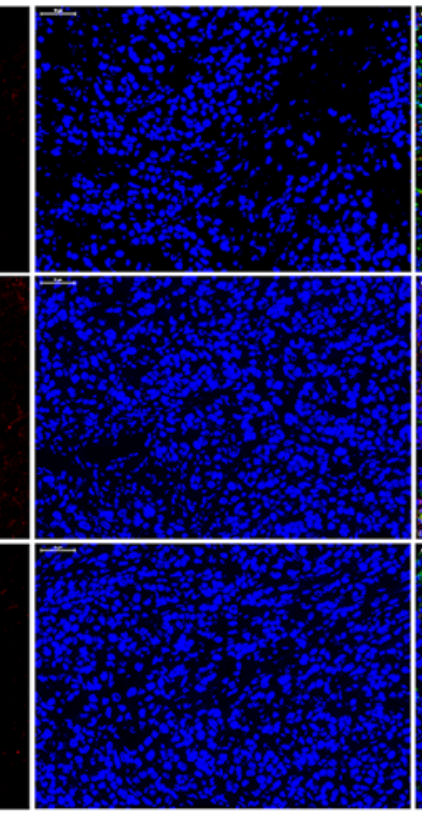

DAPI

C

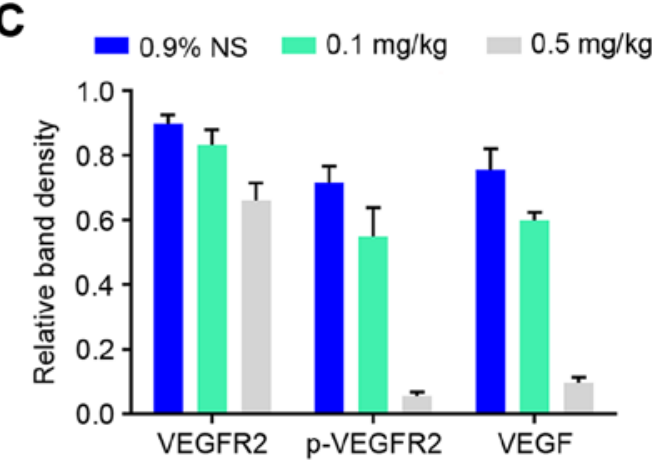

Figure 3. The P18 peptide inhibits phosphorylation of VEGFR2 in vivo. (A) Expression and distribution of VEGF and p-VEGFR2 in xenograft tumour tissues were determined by immunofluorescence photomicrography (magnification, x200). (B) Expression levels of VEGFR2, p-VEGFR2 and VEGF in tumour tissues were detected by western blot assays. (C) The density of bands in western blot assay was quantified and normalized to that of GAPDH $($ mean $\pm \mathrm{SD})$.

in Fig. 1A. Dose-response analysis achieved by CCK-8 assay confirmed an $\mathrm{IC}_{50}$ of $\sim 320 \mathrm{nmol} / \mathrm{l}$ for the P18 peptide in vitro (Fig. 1B). As a biomarker for the level of apoptosis, Bcl-2 and Bax were detected by western blotting. We treated HUVECs with different concentrations of $\mathrm{P} 18$ peptide and observed a dose-dependent downregulation of $\mathrm{Bcl}-2$ but upregulation of Bax (Fig. 1C).

P18 peptide suppresses tumour growth and angiogenesis of HCC in vivo. To evaluate the effect of the $\mathrm{P} 18$ peptide on tumour growth in vivo, we designed a xenograft tumour growth assay with HepG2 cells in nude mice. Two experimental groups received the P18 peptide at a dose of $0.1 \mathrm{mg} / \mathrm{kg}$ or $0.5 \mathrm{mg} / \mathrm{kg}$, while the control group received the same volume of $0.9 \%$ normal saline $(0.9 \% \mathrm{NS})$. The average tumour volume was $47.40 \%$ in the P18-treated $(0.1 \mathrm{mg} / \mathrm{kg})$ group and $20.64 \%$ in the P18-treated $(0.5 \mathrm{mg} / \mathrm{kg})$ group normalized to the control group (Fig. 2A and B). As hallmarks of angiogenesis, expression levels of CD31 and VE-cadherin in tumour tissues were detected by IHC analysis, which revealed a gradual decrease in CD31 and VE-cadherin with increasing dosage of P18 peptide (Fig. 2C-E). In addition, western blot assays showed a significant downregulation of expression levels of CD31 and VE-cadherin (Fig. 2F and G).

P18 peptide inhibits phosphorylation of VEGFR2 in vivo. Expression levels of VEGF and p-VEGFR2 in tumour tissues were detected by IF analysis. The results indicated that there was a dose-dependent suppression in expression of VEGF followed by a decreased phosphorylation level of VEGFR2 in P18-treated groups (Fig. 3A). Western blot assays also demonstrated that the P18 peptide downregulated the expression of VEGF and suppressed the phosphorylation of VEGFR2 in HCC tumour tissues (Fig. 3B and C).

P18 peptide suppresses EC viability by counteracting the bioactivity of VEGF in vitro. Wound healing assays and Transwell assays were performed to investigate the effects of the P18 peptide on the migration and invasive ability of ECs in the presence of VEGF, and the results suggested that the 


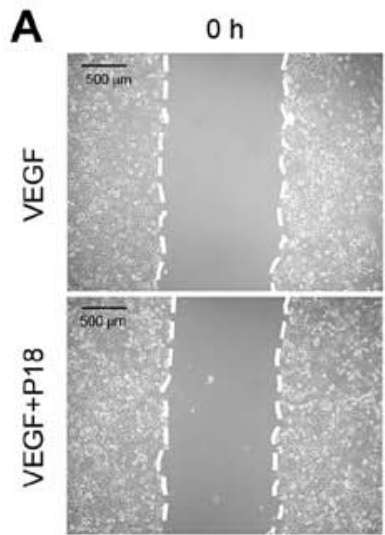

C

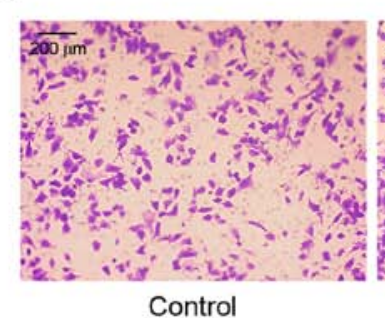

Control

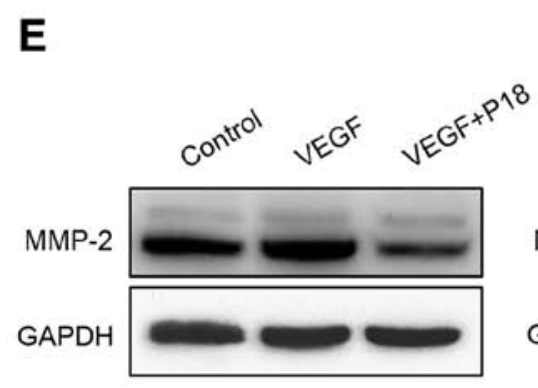

$12 \mathrm{~h}$
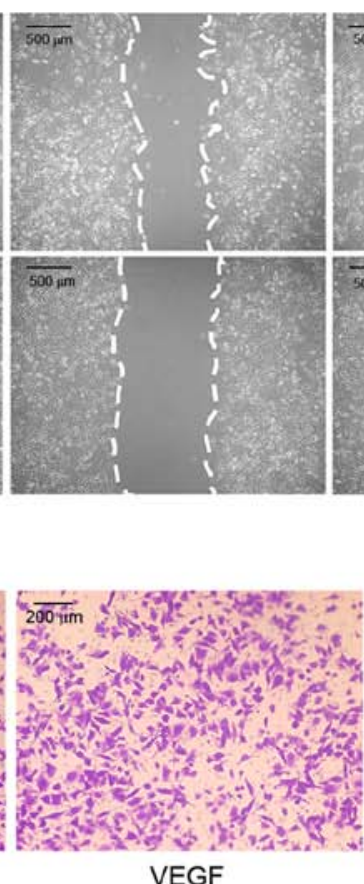

VEGF
$24 \mathrm{~h}$

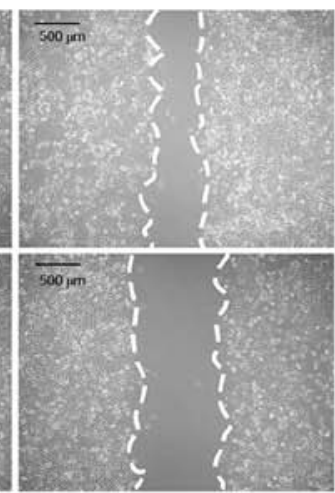

B

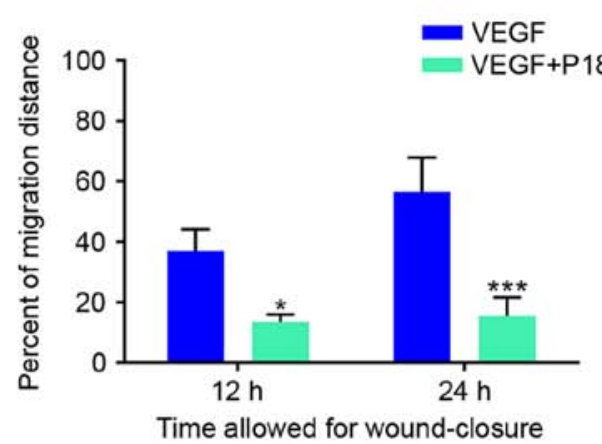

D

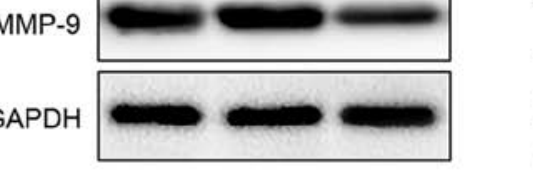

$\mathbf{F}$
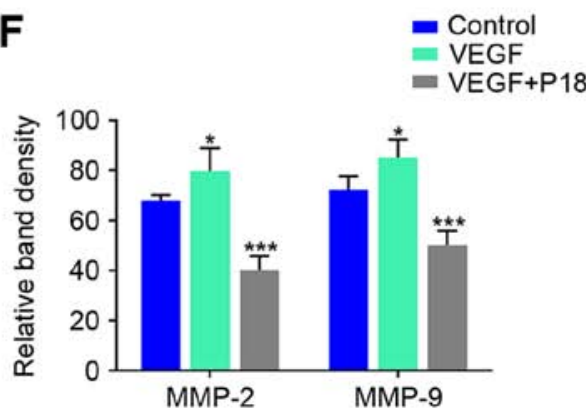

Figure 4. P18 peptide suppresses the cell viability of HUVECs and counteracts the bioactivity of VEGF in vitro. (A) The effects of the P18 peptide on HUVEC migration were analysed by a wound healing assay. (B) Data represent the migration distance as a percentage of the control group in wound healing assay (mean $\left.\pm \mathrm{SD},{ }^{*} \mathrm{P}<0.05,{ }^{* * *} \mathrm{P}<0.01\right)$. (C) The P18 peptide counteracted the bioactivity of VEGF as assessed by Transwell assays. (D) Data represent the number of cell metastases (mean $\pm \mathrm{SD},{ }^{* * *} \mathrm{P}<0.01$ ). (E) The P18 peptide counteracted the bioactivity of VEGF and downregulated expression levels of MMP-2 and MMP-9 in HUVECs as assessed by western blot assays. (F) The density of each band in western blot assay was quantified and normalized to that of GAPDH $\left(\right.$ mean $\left.\pm \mathrm{SD},{ }^{*} \mathrm{P}<0.05,{ }^{* * *} \mathrm{P}<0.01\right)$.

P18 peptide significantly inhibited HUVEC migration and invasion at a concentration of $0.2 \mu \mathrm{M}$ (Fig. 4A-D). Results of western blot assays suggested that the P18 peptide achieved this bioactivity primarily through downregulating expression levels of MMP-2 and MMP-9 in HUVECs (Fig. 4E and F). To further explore the anti-angiogenic potency of the P18 peptide in vitro, we seeded HUVECs on Matrigel-coated 96-well plates for $8 \mathrm{~h}$ using additional VEGF $(8 \mathrm{ng} / \mathrm{ml})$ as a positive control. The results indicated that VEGF could enhance angiogenesis of HUVECs but the $\mathrm{P} 18$ peptide reversed this effect and inhibited angiogenesis in vitro (Fig. $5 \mathrm{~A}$ and $\mathrm{B}$ ). At the same time, western blot assays confirmed that additional VEGF could upregulate expression levels of VE-cadherin and E-cadherin in HUVECs, while the P18 peptide counteracted this bioactivity (Fig. 5C and D).

P18 peptide induces apoptosis of ECs in vitro. Since the current study preliminarily determined an $\mathrm{IC}_{50}$ of $\sim 320 \mathrm{nmol} / \mathrm{l}$ for the
P18 peptide in vitro, we further cultured HUVECs in DMEM medium with or without VEGF. After $12 \mathrm{~h}$, PBS- dissolved P18 peptide $(0.32 \mu \mathrm{M})$ was added to the experimental group, and the cells were cultured for another $24 \mathrm{~h}$. Annexin V-FITC/ PI flow cytometry and western blot assays were used to determine the apoptosis levels of HUVECs. The results consistently indicated that additional VEGF may suppress the apoptosis of HUVECs and this process could be reversed by the P18 peptide (Fig. 6A-D).

P18 peptide suppresses HepG2 cell viability by suppressing cell migration rather than inhibiting cell proliferation inducing apoptosis. Transwell assays were performed to investigate the effects of the P18 peptide on the migration ability of HepG2 cells in the presence of VEGF. Results indicated that the P18 peptide inhibited the migration of tumour cells and counteracted the bioactivity of VEGF in vitro (Fig. 7A and B). Expression levels of MMP-2, MMP-9 and E-cadherin in 
A

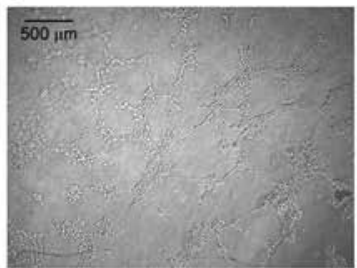

Control

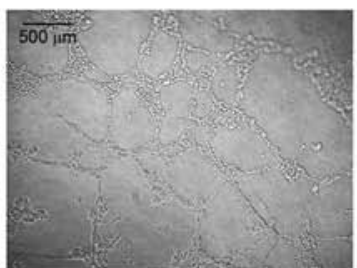

VEGF
B

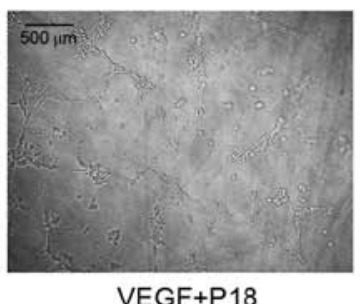

VEGF+P18

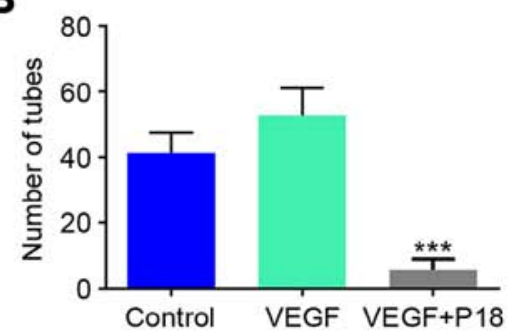

C

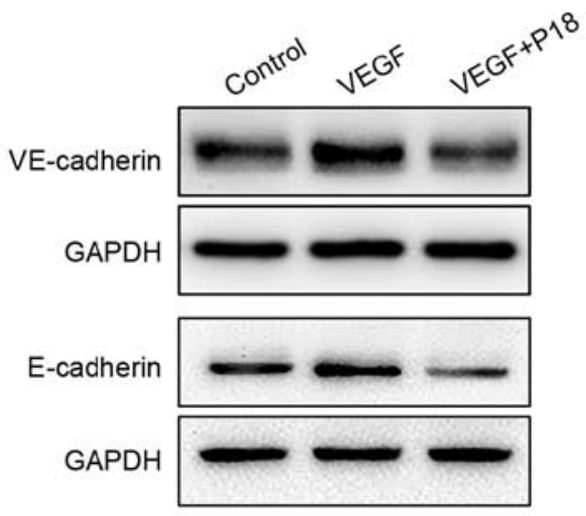

D

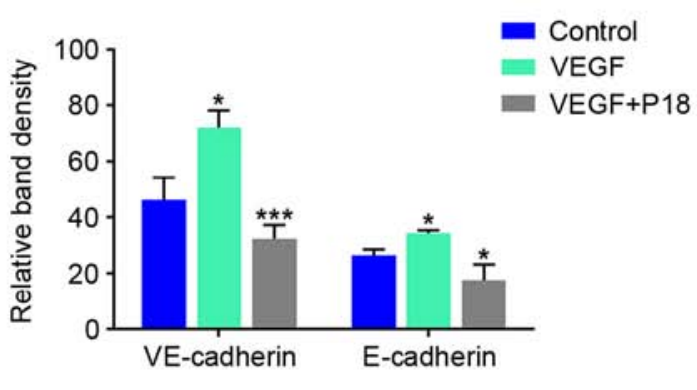

Figure 5. P18 peptide inhibits angiogenic capability of HUVECs by counteracting bioactivity of VEGF in vitro. (A) HUVECs were cultured with or without VEGF and the P18 peptide $(0.2 \mathrm{nM})$. Angiogenic capability of HUVECs was analysed by tube formation assays. (B) Data represent the number of closed tubes in the control and experimental groups (mean $\left.\pm \mathrm{SD},{ }^{*} \mathrm{P}<0.05,{ }^{* * *} \mathrm{P}<0.01\right)$. (C) The $\mathrm{P} 18$ peptide downregulated expression levels of VE-cadherin and E-cadherin in the presence of VEGF as assessed by western blot assays. (D) The density of each band in western blot assay was quantified and normalized to that of $\mathrm{GAPDH}\left(\right.$ mean $\left.\pm \mathrm{SD},{ }^{*} \mathrm{P}<0.05,{ }^{* * *} \mathrm{P}<0.01\right)$.

A
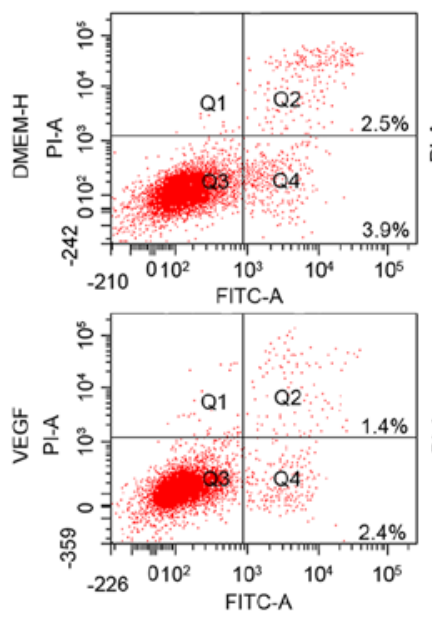

C

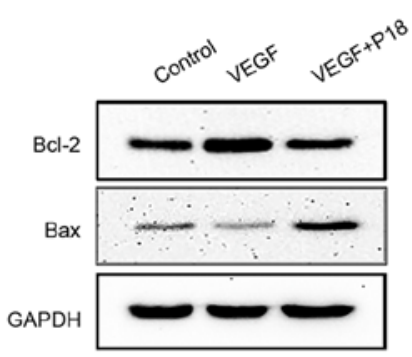

B

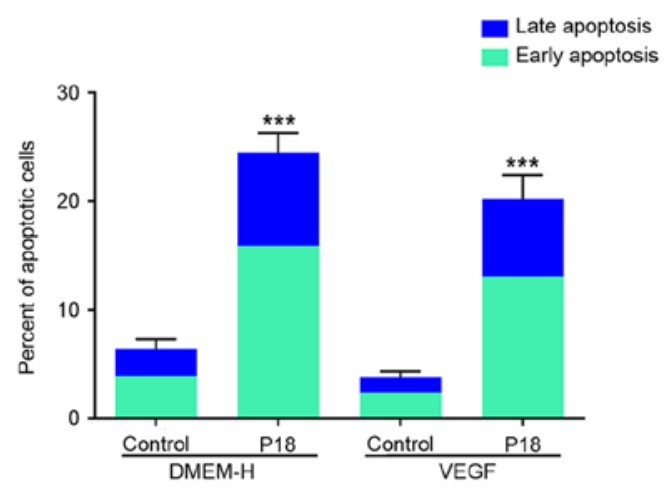

D

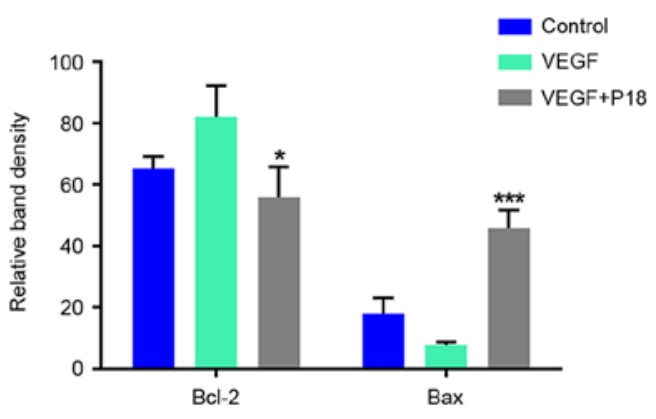

Figure 6. P18 peptide induces apoptosis of HUVECs in vitro. (A) HUVECs were cultured with or without VEGF and the P18 peptide (0.32 nM) for $24 \mathrm{~h}$. Apoptosis levels were evaluated by a flow cytometry assay. (B) Data represent the percentages of early and late apoptotic cells and are expressed as the mean $\pm \mathrm{SD},{ }^{*} \mathrm{P}<0.05,{ }^{* * * *} \mathrm{P}<0.01$. (C) Expression levels of Bcl-2 and Bax in HUVECs were analysed by western blotting after culture with or without VEGF $(8 \mathrm{ng} / \mathrm{ml})$ and the P18 peptide $(0.32 \mathrm{nM})$ for $24 \mathrm{~h}$. (D) The density of each band in western blot assay was quantified and normalized to that of GAPDH (mean $\left.\pm \mathrm{SD},{ }^{*} \mathrm{P}<0.05,{ }^{* * *} \mathrm{P}<0.01\right)$. 
A

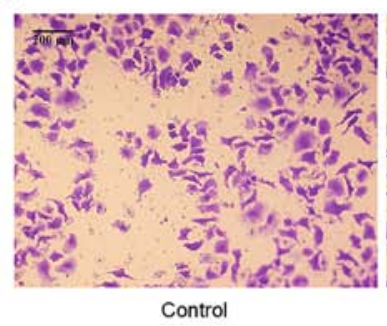

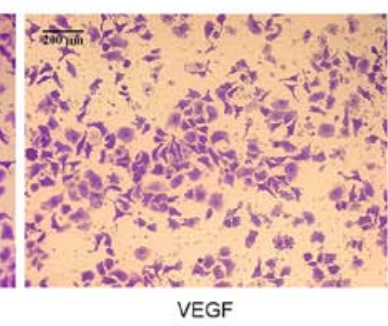

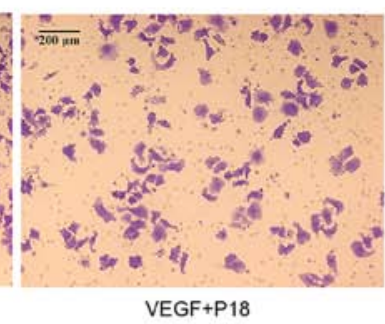

B

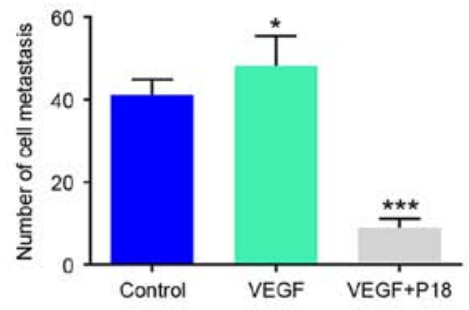

C
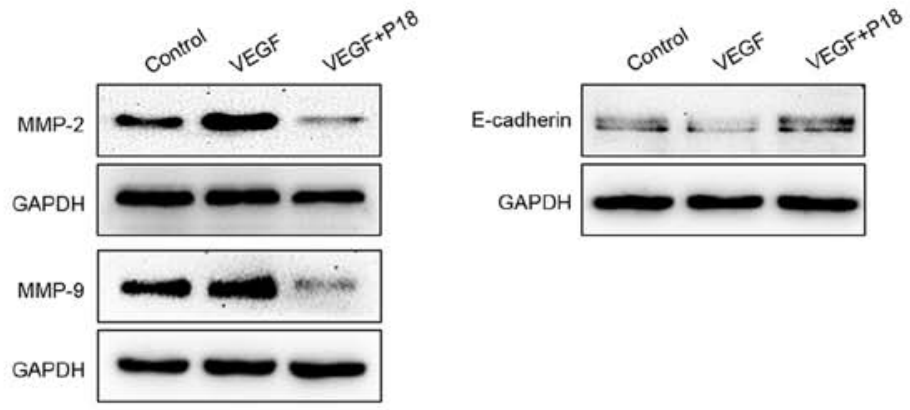

$\mathbf{E}$
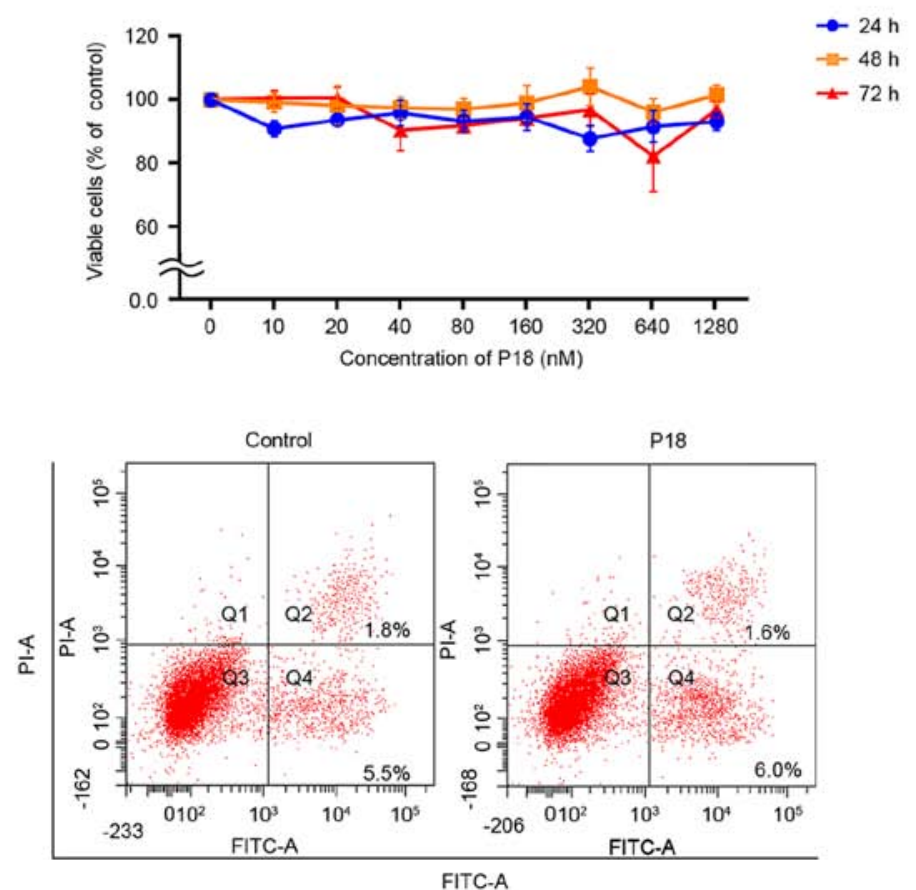

$\mathbf{F}$

FITC-A
D

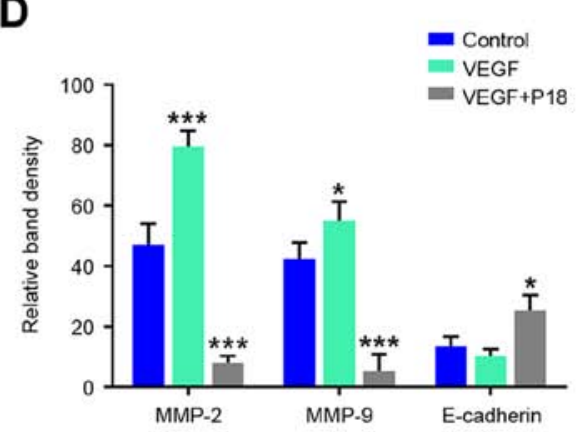

G

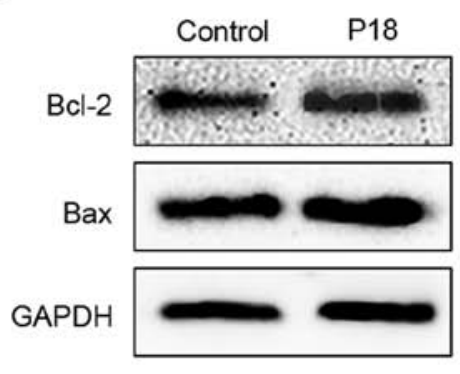

Figure 7. P18 peptide suppresses HepG2 cell viability by suppressing cell migration rather than inhibiting cell proliferation and inducing apoptosis. (A) The P18 peptide counteracted the bioactivity of VEGF and inhibited migration of HepG2 cells as assessed by Transwell assays. (B) Data represent the number of cell metastases (mean $\pm \mathrm{SD},{ }^{*} \mathrm{P}<0.05,{ }^{* * * *} \mathrm{P}<0.01$ ). (C) The P18 peptide downregulated expression levels of MMP-2 and MMP-9 in HepG2 cells as assessed by western blot assays. (D) The density of each band in western blot assay was quantified and normalized to that of GAPDH (mean \pm SD, $\left.{ }^{*} \mathrm{P}<0.05,{ }^{* * * *} \mathrm{P}<0.01\right)$. (E) Dose titration of HepG2 cell proliferation. Viable cells were quantified by CCK-8 assays. The data represent the absorbance as a percentage of their respective controls and are expressed as the mean \pm SD. (F) HepG2 cells were cultured with the P18 peptide $(0.32 \mathrm{nM})$ for $24 \mathrm{~h}$, while the control group was cultured with normal serum medium. Apoptosis levels were evaluated by a flow cytometry assay, and the results showed no significant difference. (G) Expression levels of Bcl-2 and Bax in HepG2 cells were analysed by western blot assays after culture with or without the P18 peptide (0.32 $\mathrm{nM})$ for $24 \mathrm{~h}$.

HepG2 cells treated with VEGF $(8 \mathrm{ng} / \mathrm{ml})$ and the P18 peptide $(0.32 \mu \mathrm{M})$ was determined by western blot assays. The high expression levels of MMP-2 and MMP-9 stimulated by VEGF in HepG2 cells were downregulated by the P18 peptide while the expression of E-cadherin was slightly upregulated in P18 peptide-treated groups, which contribute to the suppression of cell migration (Fig. 7C and D). However, after treatment with different concentrations of the P18 peptide for different times, no significant differences were observed in the cell proliferation of HepG2 cells in CCK-8 assays (Fig. 7E). In addition, the results of Annexin V-FITC/PI flow cytometry and western blot assays showed no significant difference in HepG2 cell apoptosis between the control and $\mathrm{P} 18$ peptide-treated groups (Fig. 7F and G). Of note, the experiments in Fig. 7E-G were 
A

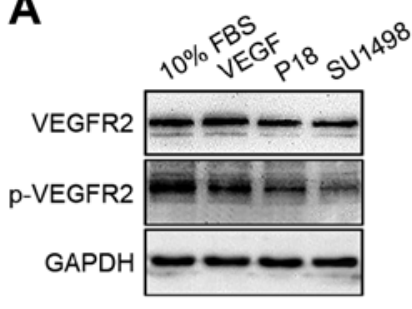

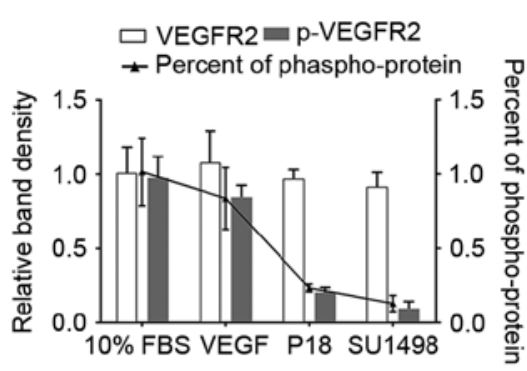

B
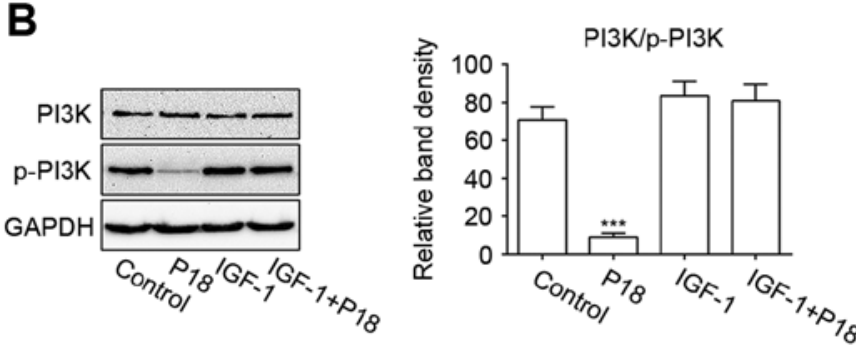

C
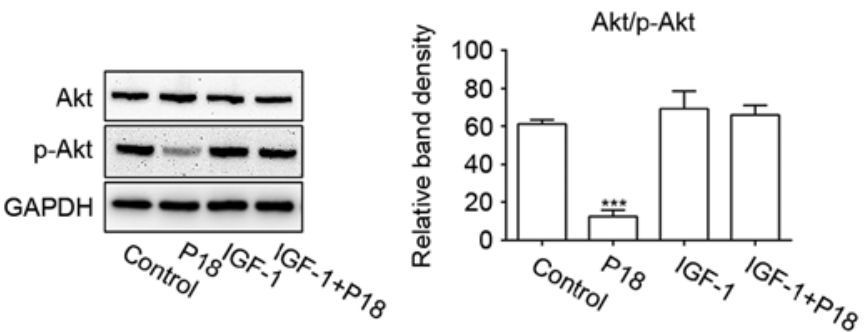

D

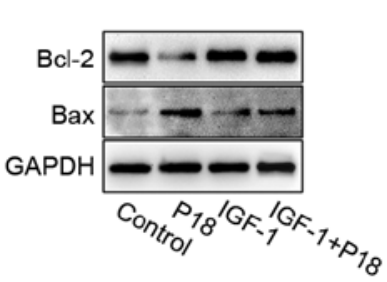

E

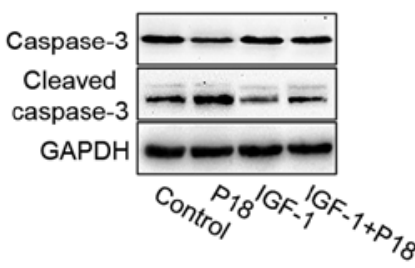

Figure 8. P18 peptide blocked VEGF/VEGFR2 signalling pathway and it induced the PI3K/Akt cascade. (A) P18 peptide inhibited the phosphorylation of VEGFR2 in a manner similar to that of SU1498. Data represent relative band density and percent of $\mathrm{p}-\mathrm{VEGFR} 2 / \mathrm{VEGFR} 2$ expressed as the mean \pm SD (B and C) The P18 peptide inhibited VEGF-induced phosphorylation of PI3K and Akt, which could be reversed by IGF-1. The data represent relative band density and are normalized to GAPDH (mean $\pm \mathrm{SD},{ }^{* * *} \mathrm{P}<0.01$ ). (D and $\mathrm{E}$ ) The P18 peptide downregulated the expression of Bcl-2, decreased the ratio of $\mathrm{Bcl}-2 / \mathrm{Bax}$, and promoted the cleavage of caspase-3, which could be reversed by IGF-1. The data represent relative band density and are normalized to GAPDH $\left(\right.$ mean $\left.\pm \mathrm{SD},{ }^{* * *} \mathrm{P}<0.01\right)$

performed in the absence of VEGF but HepG2 cells were cultured in DMEM medium with $10 \%$ FBS. Since HepG2 cells can maintain a high level of proliferation under this condition without the need for additional VEGF, we consider that cells in normal serum medium is sufficient as a control group $(28,29)$. The above results suggest that the P18 peptide suppresses HepG2 cell viability by suppressing cell migration rather than by inhibiting cell proliferation and inducing apoptosis.

P18 peptide induces EC apoptosis via blocking VEGF/ VEGFR2 and induces the PI3K/Akt signalling pathway. SU1498 is a selective inhibitor of VEGFR2, which is the major receptor for VEGF-induced bioactivity in endothelial cells $(23,30)$. In this study, we cultured HUVECs in serum-free medium with additional VEGF and used SU1498 as a positive control for the $\mathrm{P} 18$ peptide. HUVECs cultured in medium with $10 \%$ FBS or VEGF served as a negative control. The western blot results showed that the P18 peptide inhibited VEGFinduced phosphorylation of VEGFR2 in a manner similar to that of SU1498 (Fig. 8A). To further demonstrate the mechanism by which P18 inhibits angiogenesis, we treated HUVECs in serum-free medium for $24 \mathrm{~h}$ and then replaced the medium with additional VEGF with or without the P18 peptide $(0.2 \mu \mathrm{M})$. IGF-1, an activator of PI3K/Akt pathway, was used as a nega- tive control (31). As downstream signalling axis of VEGFR2, the activation of PI3K and Akt through phosphorylation in the HUVECs were significantly suppressed after treatment with the P18 peptide for $90 \mathrm{~min}$, which could be reversed with presence of IGF-1 $(0.2 \mathrm{ng} / \mathrm{ml})$ (Fig. $8 \mathrm{~B}$ and C). After culturing with the $\mathrm{P} 18$ peptide or IGF-1 for $4 \mathrm{~h}, \mathrm{Bcl}-2 / \mathrm{Bax}$, as biomarkers for the extent of apoptosis, and their downstream target molecules, cleaved caspase-3/caspase-3, were also detected by western blotting. The results indicated that the P18 peptide suppressed the expression of Bcl-2, induced the expression of Bax and enhanced the proteolytic processing of inactive caspase- 3 into cleaved caspase-3. However, these effects were counteracted by IGF-1 (Fig. 8D and E). These results indicated that deactivation of the VEGF/VEGFR2 signalling pathway and it induced PI3K/Akt cascades may be a protective mechanism involved in the P18 peptide-induced apoptosis of HUVECs and its antiangiogenic activity.

\section{Discussion}

As a type of richly vascularized solid tumour, the occurrence and development of HCC is highly dependent on angiogenesis (5). Therefore, anti-angiogenic treatments have become clinically significant therapeutic options for the treatment 
of HCC patients (7). Angiogenesis is primarily subject to pro-angiogenic and anti-angiogenic factors. PEDF, a type of endogenous angiogenesis inhibitor, has been confirmed as a multifunctional antitumour factor. It has been reported that PEDF inhibits angiogenesis by inducing apoptosis of ECs and several types of tumour cells $(10,16)$. Full-length PEDF has several functional sections, and the anti-angiogenic functional fragment is located from residues 24 to 57 (known as PEDF-34mer) $(13,32)$. In the current study, our data indicated that the $\mathrm{P} 18$ peptide, a functional fragment mapping to residues 40 to 57 of full-length PEDF, exerts anti-angiogenic activity both in vitro and in vivo. Compared with full-length PEDF, the P18 peptide is more stable and biocompatible but exhibits low antigenicity, which indicates the potential of the P18 peptide for application in anti-angiogenic therapy in HCC patients.

In the current study, the $\mathrm{P} 18$ peptide was confirmed to have an anti-angiogenic effect on HCC in vivo. CD31 is primarily concentrated at the borders between endothelial cells and can be considered as a biomarker of angiogenesis. Studies have demonstrated that in endothelial cells, VE-cadherin signalling, expression, and localization correlate with vascular permeability and tumour angiogenesis (33). IHC staining of CD31 and VE-cadherin in tumour tissues suggested that the P18 peptide functions as a potent inhibitor of angiogenesis in vivo. Moreover, IF staining images indicated that suppression of the phosphorylation of VEGFR2 may be the mechanism by which the P18 peptide achieves its functions.

Angiogenesis relies on EC destabilization, dissociation and migration. With the rapid growth of solid tumours, the hypoxic environment inside tumour tissues stimulates the expression of matrix metalloproteinases and pro-angiogenic cytokines, such as MMP-2, MMP-9, VE-cadherin and E-cadherin (34). MMP-2 and MMP-9 are available from HUVECs and is responsible for tissue remodelling during carcinogenesis, tumour metastasis and angiogenesis $(35,36)$. Our study showed that additional VEGF may upregulate secretions of MMP-2 and MMP-9 in HUVECs, which corresponds to the results of HUVEC migration and invasion assays. However, HUVECs treated with P18 peptide show no response to additional VEGF. Moreover, we observed similar results in expression levels of MMP-2 and MMP-9 in HepG2 cells treated with P18 peptide. The results above certainly suggest that the P18 peptide may perform its anti-angiogenic function by inhibiting biological activity of VEGF. However, opposite results were shown in the effects of $\mathrm{P} 18$ peptide on E-cadherin expression in HUVECs and HepG2 cells. The upregulation of E-cadherin in HepG2 cells is responsible for the suppression of cell migration $(37,38)$. The expression of E-cadherin in HUVECs showed a decreasing trend. We consider that the decline in cell activity after treatment with the P18 peptide may be connected to this phenomenon. As an adhesion protein between cells, the reduced expression of E-cadherin may lead to instability and disintegration of vascular structures. However, the exact mechanism by which the P18 peptide downregulated expression of E-cadherin in HUVECs needs further study, which will be the next step of our research.

Similar to parental PEDF and PEDF-34mer, the P18 peptide inhibits proliferation and induces apoptosis of HUVECs in vitro and has an $\mathrm{IC}_{50}$ of $320 \mathrm{nM}$. The Bcl-2 family consists of many evolutionarily conserved proteins that can regulate cell apoptosis through the classical mitochondrial apoptosis pathway (39). Bcl-2 is an anti-apoptotic protein in this family, whereas Bax is a pro-apoptotic protein. Interactions between death-promoting and death-suppressing factors regulate a dynamic equilibrium in which the ratio between anti-apoptotic and pro-apoptotic proteins controls cell apoptosis (40). According to our results, HUVECs maintain a low level of apoptosis under a certain concentration of VEGF $(8 \mathrm{ng} / \mathrm{ml})$. The P18 peptide significantly increases the rate of apoptosis accompanied by downregulation of both the expression of $\mathrm{Bcl}-2$ and the ratio of $\mathrm{Bcl}-2 / \mathrm{Bax}$. However, according to our results, treatment with the P18 peptide does not change the apoptosis rate of $\mathrm{HepG} 2$ cells.

Based on these results, we conjecture that the $\mathrm{P} 18$ peptide inhibits angiogenesis by blocking VEGF/VEGFR2 axis and inducing apoptosis of endothelial cells. VEGF, which is produced by a number of cells including endothelial cells, macrophages and different types of tumour cells, is involved in angiogenesis, vascular endothelial cell survival, proliferation and vascular permeability $(3,20)$. The results of the migration and tube-formation assays showed that the P18 peptide could inhibit ECs migration and angiogenic capacity induced by VEGF treatment. To further account for these phenomena, the phosphorylation of VEGFR2 in HUVECs was detected. As a major receptor of VEGF, VEGFR2-induced signalling is necessary for the execution of VEGF-stimulated survival, the migration of ECs and angiogenesis in the development of tumours $(18,22)$. Phosphorylation of VEGFR2 leads to activation of downstream signalling pathways, including the MAPK/Erk and PI3K/Akt pathways $(22,26)$.

According to our data, lower phosphorylation levels of VEGFR2 in HUVECs were observed after culturing in serumfree medium for $24 \mathrm{~h}$, and those changes were rapidly reversed in the presence of serum or additional VEGF. However, this reversal was abrogated when the P18 peptide was simultaneously added to the medium. The same result was also observed when SU1498 was added instead of the P18 peptide. We noted that treatment with the P18 peptide also downregulated the phosphorylation levels of PI3K and Akt induced by VEGF, whereas the ratio of p-PI3K/PI3K and p-Akt/Akt can be upregulated upon treatment with IGF-1, an activator of the PI3K/Akt pathway. In addition, we investigated variations in the expression of Bcl-2/Bax among HUVECs treated with the P18 peptide, the control group and the IGF-1-treated group. Since previous studies have demonstrated that a reduction in Bcl-2/Bax leads to the cleavage of caspase members and initiates a caspase cascade, which results in activation and amplification of cell apoptotic responses (41-43), we detected cleaved caspase- 3 and total caspase- 3 as indexes for evaluating apoptosis. According to the western blot results, we confirmed that the P18 peptide downregulated the expression of Bcl-2 and the ratio of Bcl-2/Bax, accompanied by enhanced cleavage of caspase-3 in synchronism with an inhibition of PI3K/Akt pathway. Consequently, treatment of the $\mathrm{P} 18$ peptide was associated with enhanced mitochondrial-mediated apoptosis.

In summary, the P18 peptide exerts its anti-angiogenic bioactivity by inhibiting endothelial cell viability and inducing apoptosis. Simultaneously, the P18 peptide suppresses tumour cell viability by inhibiting cell migration rather than inducing apoptosis in HCC. VEGFR2 is the primary target of the P18 
peptide acting in ECs. Via modulating VEGF/VEGFR2 and it induced PI3K/Akt signalling pathway, the P18 peptide enhances mitochondrial-mediated apoptosis in ECs and suppresses vessel formation in tumour tissues. This antiangiogenic activity of the P18 peptide suggests that it may be a potential agent for the treatment of HCC.

\section{Acknowledgements}

This study was supported by the National Major Research and Development Program of China (2016YFC0106004), Shandong Provincial Science and Technology Development Planning, China (2015GGB14168) and Shandong Provincial Natural Science Foundation, China (ZR2015HL080).

\section{References}

1. Carmeliet P: Angiogenesis in life, disease and medicine. Nature 438: 932-936, 2005.

2. Hanahan D and Folkman J: Patterns and emerging mechanisms of the angiogenic switch during tumorigenesis. Cell 86: 353-364, 1996.

3. Schlieve CR, Mojica SG, Holoyda KA, Hou X, Fowler KL and Grikscheit TC: Vascular endothelial growth factor (VEGF) bioavailability regulates angiogenesis and intestinal stem and progenitor cell proliferation during postnatal small intestinal development. PLoS One 11: e0151396, 2016.

4. Li Y, Turpin CP and Wang S: Role of thrombospondin 1 in liver diseases. Hepatol Res: Aug 4, 2016 (Epub ahead of print).

5. Zhu AX, Duda DG, Sahani DV and Jain RK: HCC and angiogenesis: Possible targets and future directions. Nat Rev Clin Oncol 8: 292-301, 2011.

6. Atta MM, Atta HM, Gad MA, Rashed LA, Said EM, Hassanien Sel-S and Kaseb AO: Clinical significance of vascular endothelial growth factor in hepatitis $\mathrm{C}$ related hepatocellular carcinoma in Egyptian patients. J Hepatocell Carcinoma 3: 19-24, 2016.

7. Welker MW and Trojan J: Anti-angiogenesis in hepatocellular carcinoma treatment: Current evidence and future perspectives. World J Gastroenterol 17: 3075-3081, 2011.

8. Edeline J, Boucher E, Rolland Y, Vauléon E, Pracht M, Perrin C, Le Roux C and Raoul JL: Comparison of tumor response by Response Evaluation Criteria in Solid Tumors (RECIST) and modified RECIST in patients treated with sorafenib for hepatocellular carcinoma. Cancer 118: 147-156, 2012.

9. Dawson DW, Volpert OV, Gillis P, Crawford SE, Xu H, Benedict W and Bouck NP: Pigment epithelium-derived factor: A potent inhibitor of angiogenesis. Science 285: 245-248, 1999.

10. He X, Cheng R, Benyajati S and Ma JX: PEDF and its roles in physiological and pathological conditions: Implication in diabetic and hypoxia-induced angiogenic diseases. Clin Sci (Lond) 128: $805-823,2015$

11. Belkacemi L and Zhang SX: Anti-tumor effects of pigment epithelium-derived factor (PEDF): Implication for cancer therapy. A mini-review. J Exp Clin Cancer Res 35: 4, 2016.

12. Smith ND, Schulze-Hoepfner FT, Veliceasa D, Filleur S, Shareef S, Huang L, Huang XM and Volpert OV: Pigment epithelium-derived factor and interleukin-6 control prostate neuroendocrine differentiation via feed-forward mechanism. J Urol 179: 2427-2434, 2008.

13. Filleur S, Volz K, Nelius T, Mirochnik Y, Huang H, Zaichuk TA, Aymerich MS, Becerra SP, Yap R, Veliceasa D, et al: Two functional epitopes of pigment epithelial-derived factor block angiogenesis and induce differentiation in prostate cancer. Cancer Res 65: 5144-5152, 2005

14. He SS, Shi HS, Yin T, Li YX, Luo ST, Wu QJ, Lu L, Wei YQ and Yang L: AAV-mediated gene transfer of human pigment epithelium-derived factor inhibits Lewis lung carcinoma growth in mice. Oncol Rep 27: 1142-1148, 2012.

15. Broadhead ML, Dass CR and Choong PF: Systemically administered PEDF against primary and secondary tumours in a clinically relevant osteosarcoma model. Br J Cancer 105: $1503-1511,2011$
16. Hase R, Miyamoto M, Uehara H, Kadoya M, Ebihara Y, Murakami Y, Takahashi R, Mega S, Li L, Shichinohe T, et al: Pigment epithelium-derived factor gene therapy inhibits human pancreatic cancer in mice. Clin Cancer Res 11: 8737-8744, 2005.

17. Mirochnik Y, Aurora A, Schulze-Hoepfner FT, Deabes A, Shifrin V, Beckmann R, Polsky C and Volpert OV: Short pigment epithelial-derived factor-derived peptide inhibits angiogenesis and tumor growth. Clin Cancer Res 15: 1655-1663, 2009.

18. Hicklin DJ and Ellis LM: Role of the vascular endothelial growth factor pathway in tumor growth and angiogenesis. J Clin Oncol 23: 1011-1027, 2005.

19. Zsebik B, Symonowicz K, Saleh Y, Ziolkowski P, Bronowicz A and Vereb G: Photodynamic therapy combined with a cysteine proteinase inhibitor synergistically decrease VEGF production and promote tumour necrosis in a rat mammary carcinoma. Cell Prolif 40: 38-49, 2007.

20. Kazemi M, Carrer A, Moimas S, Zandonà L, Bussani R, Casagranda B, Palmisano S, Prelazzi P, Giacca M, Zentilin L, et al: VEGF121 and VEGF165 differentially promote vessel maturation and tumor growth in mice and humans. Cancer Gene Ther 23: 125-132, 2016.

21. Frezzetti D, Gallo M, Roma C, D'Alessio A, Maiello MR, Bevilacqua S, Normanno $\mathrm{N}$ and De Luca A: Vascular endothelial growth factor a regulates the secretion of different angiogenic factors in lung cancer cells. J Cell Physiol 231: 1514-1521, 2016.

22. Olsson AK, Dimberg A, Kreuger J and Claesson-Welsh L: VEGF receptor signalling - in control of vascular function. Nat Rev Mol Cell Biol 7: 359-371, 2006.

23. Robinson CJ and Stringer SE: The splice variants of vascular endothelial growth factor (VEGF) and their receptors. J Cell Sci 114: 853-865, 2001.

24. Domigan CK, Ziyad S and Iruela-Arispe ML: Canonical and noncanonical vascular endothelial growth factor pathways: New developments in biology and signal transduction. Arterioscler Thromb Vasc Biol 35: 30-39, 2015.

25. Smith NR, Baker D, James NH, Ratcliffe K, Jenkins M, Ashton SE, Sproat G, Swann R, Gray N, Ryan A, et al: Vascular endothelial growth factor receptors VEGFR-2 and VEGFR-3 are localized primarily to the vasculature in human primary solid cancers. Clin Cancer Res 16: 3548-3561, 2010.

26. Holmqvist K, Cross MJ, Rolny C, Hägerkvist R, Rahimi N, Matsumoto T, Claesson-Welsh L and Welsh M: The adaptor protein shb binds to tyrosine 1175 in vascular endothelial growth factor (VEGF) receptor-2 and regulates VEGF-dependent cellular migration. J Biol Chem 279: 22267-22275, 2004.

27. Johnston EK, Francis MK and Knepper JE: Recombinant pigment epithelium-derived factor PEDF binds vascular endothelial growth factor receptors 1 and 2. In Vitro Cell Dev Biol Anim 51: 730-738, 2015.

28. Wu LF, Ye YQ, Huang GY, Li HB, Li GP, Pu ZJ, Wei BL and Feng JL: Involvement of endoplasmic reticulum stress in adenosine-induced human hepatoma HepG2 cell apoptosis. Oncol Rep 26: 73-79, 2011.

29. Donato MTTL, Tolosa L and Gómez-Lechón MJ: Culture and functional characterization of human hepatoma HepG2 cells. Methods Mol Biol 1250: 77-93, 2015.

30. Kisielewska J, Ligeza J and Klein A: The effect of tyrosine kinase inhibitors, tyrphostins: AG1024 and SU1498, on autocrine growth of prostate cancer cells (DU145). Folia Histochem Cytobiol 46: 185-191, 2008.

31. Laurino L, Wang XX, de la Houssaye BA, Sosa L, Dupraz S, Cáceres A, Pfenninger KH and Quiroga S: PI3K activation by IGF-1 is essential for the regulation of membrane expansion at the nerve growth cone. J Cell Sci 118: 3653-3662, 2005.

32. Gong Q, Qiu S, Li S, Ma Y, Chen M, Yao Y, Che D, Feng J, Cai W, Ma J, et al: Proapoptotic PEDF functional peptides inhibit prostate tumor growth - a mechanistic study. Biochem Pharmacol 92: 425-437, 2014

33. Coon BG, Baeyens N, Han J, Budatha M, Ross TD, Fang JS, Yun S, Thomas JL and Schwartz MA: Intramembrane binding of VE-cadherin to VEGFR2 and VEGFR3 assembles the endothelial mechanosensory complex. J Cell Biol 208: 975-986, 2015.

34. Liao D and Johnson RS: Hypoxia: A key regulator of angiogenesis in cancer. Cancer Metastasis Rev 26: 281-290, 2007.

35. Sternlicht MD and Werb Z: How matrix metalloproteinases regulate cell behavior. Annu Rev Cell Dev Biol 17: 463-516, 2001.

36. Li H, Daculsi R, Bareille R, Bourget C and Amedee J: uPA and MMP-2 were involved in self-assembled network formation in a two dimensional co-culture model of bone marrow stromal cells and endothelial cells. J Cell Biochem 114: 650-657, 2013. 
37. Zhao Y, Peng S, Jia C, Xu F, Xu Y and Dai C: Armc8 regulates the invasive ability of hepatocellular carcinoma through E-cadherin/ catenin complex. Tumour Biol 37: 11219-11224, 2016.

38. Yu AQ, Ding Y, Li CL, Yang Y, Yan SR and Li DS: TALENinduced disruption of Nanog expression results in reduced proliferation, invasiveness and migration, increased chemosensitivity and reversal of EMT in HepG2 cells. Oncol Rep 35: $1657-1663,2016$.

39. Cory S, Huang DC and Adams JM: The Bcl-2 family: Roles in cell survival and oncogenesis. Oncogene 22: 8590-8607, 2003

40. Cory S and Adams JM: The Bcl2 family: Regulators of the cellular life-or-death switch. Nat Rev Cancer 2: 647-656, 2002.
41. Li LY, Luo $X$ and Wang $X$ : Endonuclease $G$ is an apoptotic DNase when released from mitochondria. Nature 412: 95-99, 2001.

42. Tian X, Shi Y, Liu N, Yan Y, Li T, Hua P and Liu B: Upregulation of DAPK contributes to homocysteine-induced endothelial apoptosis via the modulation of $\mathrm{Bcl} 2 / \mathrm{Bax}$ and activation of caspase 3. Mol Med Rep 14: 4173-4179, 2016.

43. Cao Y, Jiang Z, Zeng Z, Liu Y, Gu Y, Ji Y, Zhao Y and Li Y: Bcl-2 silencing attenuates hypoxia-induced apoptosis resistance in pulmonary microvascular endothelial cells. Apoptosis 21: 69-84, 2016. 